\title{
Morphological, mechanical, and optical properties of cypress papers
}

Ofélia Anjos1, 2/ António J. A. Santos2, 3/ Rogério Simões3 / Helena Pereira2

1Instituto Politécnico de Castelo Branco, Escola Superior Agrária, Apartado 119, 6001-909

Castelo Branco, Portugal

${ }_{2}$ Centro de Estudos Florestais, Instituto Superior de Agronomia, Universidade de Lisboa, Tapada da Ajuda, 1349-017 Lisboa, Portugal

3Universidade da Beira Interior, Unidade de Materiais Têxteis e Papeleiros 6201-001 Covilhã,

Portugal

Corresponding author: Helena Pereira, Centro de Estudos Florestais, Instituto Superior de

Agronomia, Universidade de Lisboa, Tapada da Ajuda, 1349-017 Lisboa, Portugal, e-mail:

(email)

Citation Information: Holzforschung. Volume 0, Issue 0, ISSN (Online) 1437-434X, ISSN

(Print) 0018-3830, DOI: 10.1515/hf-2013-0125, March 2014

Publication History: Received: 2013-07-08; Accepted: 2014-02-24; Published Online: 2014-03-21

\section{Abstract}

The pulping properties of cypress species are not known and the present paper aims to filling this gap. Namely, Cupressus lusitanica Mill., C. sempervirens $L$. and C. arizonica Greene have been submitted to kraft pulping and the pulp properties are compared with those of Pinus pinaster Aiton. and P. sylvestris Watereri as references. Schopper Riegler degree, density, Bekk's smoothness, tensile index, tear index, burst index, stretch, dry zerospan strength, wet zero-span strength, brightness, opacity and light scattering coefficient have been tested. The pulp yields and delignification degrees of cypress woods were lower than those of the pine references. Fibre length, width and coarseness were statistically different between pines and cypress species and $C$. sempervirens pulps have corresponding data close to those of pine species. Cypress pulps can be refined much faster than pine pulps. The papers sheets of cypress fibres have, in general, lower mechanical performance than those of pine fibres. Papers from $C$. arizonica and $C$. lusitanica are similar and $C$. sempervirens has intermediate properties being between the other cypress and pine species. However, cypress fibres are relatively short, flexible and collapsible and can be refined with low energy demand, and thus could be incorporated into papers resulting in products with better light scattering and smoothness.

Keywords: Bekk's smoothness; brightness; burst index; Cupressus arizonica; Cupressus lusitanica; Cupressus sempervirens; density; dry zero-span strength; light scattering; opacity paper properties; papermaking potential; Schopper-Riegler degree; stretch; tear index; tensile index; wet zero-span strength 